TITLE:

\title{
Altitudinal variation in life-history traits in the lawn ground cricket, Polionemobius mikado
}

$\operatorname{AUTHOR}(\mathrm{S})$ :

Matsuda, Naoki; Numata, Hideharu

\section{CITATION:}

Matsuda, Naoki ...[et al]. Altitudinal variation in life-history traits in the lawn ground cricket, Polionemobius mikado. Entomological Science 2019, 22(2): 198-204

\section{ISSUE DATE:}

2019-06

URL:

http://hdl.handle.net/2433/241613

\section{RIGHT:}

This is the peer reviewed version of the following article: Matsuda, N. and Numata, H. (2019), Altitudinal variation in life - history traits in the lawn ground cricket, Polionemobius mikado. Entomological Science, 22: 198-204, which has been published in final form at https://doi.org/10.1111/ens.12359. This article may be used for non-commercial purposes in accordance with Wiley Terms and Conditions for Use of Self-Archived Versions.: The full-text file will be made open to the public on 23 May 2020 in accordance with publisher's 'Terms and Conditions for Self-Archiving': This is not the published version. Please cite only the published version.; この論文は出版社版でありません。引用の際には 出版社版をご確認ご利用ください。 
Altitudinal variation in life-history traits in the lawn ground cricket, Polionemobius mikado

Running head: Altitudinal variation in a cricket

Naoki MATSUDA and Hideharu NUMATA*

Graduate School of Science, Kyoto University, Sakyo, Kyoto 606-8502, Japan

* Corresponding author at Graduate School of Science, Kyoto University, Sakyo, Kyoto 606-8502, Japan. Tel.: +81 75753 4073; fax: +81 757534113

E-mail address: numata@ethol.zool.kyoto-u.ac.jp (H. Numata) 
Abstract

It has been reported that the lawn ground cricket, Polionemobius mikado (Orthoptera: Trigonidiidae), shows variations in voltinism and life-history traits along latitude in Japan, but whether it shows variations along altitude has not been examined. The present study aims to determine whether there is variation in voltinism, body size and the incidence of embryonic diapause among populations of $P$. mikado at different altitudes in Kyoto, Japan. Six populations collected from 70 to $800 \mathrm{~m}$ above sea level showed a positive relationship between the adult head width and the altitude of sampling locality. This body size cline is attributed to the increasing proportion of larger univoltine individuals from low to high altitude. The incidence of diapause of the strain from altitude $800 \mathrm{~m}$ was approximately $100 \%$ when reared under natural photoperiods and temperatures from spring to summer at an altitude of $70 \mathrm{~m}$, and was significantly higher than that of the strain from $70 \mathrm{~m}$. These differences in life-history traits suggest that the population of $P$. mikado at a higher altitude has adapted to a shorter length of the season available for growth.

Key words: body size, embryonic diapause, growing season, voltinism 


\section{INTRODUCTION}

Many insect species distributed broadly along latitudinal and altitudinal gradients show intraspecific variation in their seasonal life cycle due to the diversity in climatic conditions (Tauber \& Tauber 1981). Because the average air temperature becomes lower at higher latitudes and drops on average by $6^{\circ} \mathrm{C}$ per $1,000 \mathrm{~m}$ of altitude (Körner 2007; Hut et al. 2013), the length of the season suitable for growth of an insect is shortened with increasing latitude and altitude. In addition, insects show a marked shift in body size along a latitudinal gradient (Blanckenhorn \& Demont 2004; Shelomi 2012). The body size often increases with increasing latitude, because lower temperature generally results in larger body size (Atkinson 1994). However, the differing length of the growing season has been postulated to be the main cause of the negative relationship between body size and latitude (Masaki 1967; Chown \& Gaston 1999). This is because shorter development time generally results in smaller body size (Roff 1980), even though growth rate is often variable (Dmitriew 2011). If the number of annual generations is greater at lower latitude, insects often show a "saw-tooth cline" between adult body size and latitude, because the development time per generation abruptly decreases where the number of annual generations increases (Masaki 1972; Roff 1980; Chown \& Gaston 1999; Matsuda et al. 2018). As in the case of the latitudinal adaptation, insects often compensate for a shorter growing season at higher altitude by reducing their development time or the number of annual generations, together with shifts in times of diapause induction and termination (Hodkinson 2005). Intraspecific variations in field phenology along altitudinal gradients have been reported in Orthoptera (Alexander \& Hilliard 1969; Dearn 1977; Tanaka \& Brookes 1983; Dingle et al. 1990; 
Higaki \& Ando 1999; Berner et al. 2004). Moreover, a negative relationship between adult body size and altitude has been observed in several species in Orthoptera, e.g. Teleogryllus emma, Omocestus viridulus, Poecilimon veluchianus (Masaki 1967; Berner \& Blanckenhorn 2006; Bidau \& Martí 2007; Laiolo et al. 2013; Eweleit \& Reinhold 2014; Levy \& Nufio 2015). Although a few studies have shown genetic differences in life-history traits (Dingle et al. 1990; Berner et al. 2004), whether these phenotypic differences have genetic bases or result from plastic responses to environments is often unclear (Keller et al. 2013).

The lawn ground cricket, Polionemobius mikado (Shiraki, 1913) (Orthoptera: Trigonidiidae), formerly known as Pteronemobius taprobanensis, is widely distributed in Japan. This species overwinters as eggs. There are bivoltine populations in the southern part of Japan: Adults of the overwintering generation emerge in summer and produce nondiapause eggs that hatch within a month, whereas those of the next generation emerge in autumn and produce diapause eggs. In the northern part of Japan, however, there are univoltine populations: Adults of the overwintering generation emerge in autumn and produce diapause eggs. Masaki (1978a, 1978b) showed that adult P. mikado collected in autumn showed a latitudinal saw-tooth cline in the head width due to the variation in voltinism: The head width slightly decreases northward to about $33^{\circ} \mathrm{N}$, then increases to about $39^{\circ} \mathrm{N}$ and again decreases to about $43^{\circ} \mathrm{N}$. Moreover, Masaki (1979) showed genetic differences in the incidence of embryonic diapause related to the variation in voltinism among the latitudes where the P. mikado originated. Similarly, altitudinal variation in voltinism is expected to be observed in P. mikado. Body size of univoltine populations at higher altitudes may be larger than that of bivoltine populations at lower altitudes (Roff 1980). Their genetic propensity to enter 
diapause may also adapt to the shorter length of the season available for growth at higher altitudes.

The present study aims to examine the variation in voltinism and life-history traits along an altitudinal gradient in P. mikado. First, we examined the incidence of embryonic diapause of a natural population at a low altitude in summer and autumn to determine whether the low-altitude population was bivoltine. Second, we measured the body size of populations collected from six sites at different altitudes, and estimated their voltinism based on the relationship between the body size and altitude. Finally, we reared two strains originating from low- and high-altitude populations at different altitudes under natural photoperiods and temperatures at a low altitude site to examine whether the high-altitude population produces nondiapause eggs in summer and shows a bivoltine life cycle at a low altitude.

\section{MATERIALS AND METHODS}

\section{Insects}

Adults of P. mikado were collected from six sites in Kyoto City and in a nearby city, Otsu City, Japan, from July to September in 2015-2017 (Fig. 1). The sites ranged from 70 to $800 \mathrm{~m}$ above sea level. The distance from the lowest site (Site 1) to the highest site (Site 6) was approximately $5.7 \mathrm{~km}$. Adults and nymphs of P. mikad were reared on dried pellets for insects (Oriental Yeast, Tokyo, Japan) and pieces of carrot. Folded paper towels were served as shelters. Moist cotton was served both as a water source and oviposition site. 


\section{Season length at different altitudes}

The sum of effective temperatures for development of $P$. mikado from spring to autumn was calculated for the six sampling sites as an index for the length of the season available for growth. The end of the growing season was defined as the first day after which the daily mean temperature fell below the lower development threshold for more than two successive days. The lower development threshold was calculated as $11.7^{\circ} \mathrm{C}$ from the data of Masaki (1960), based on a linear regression analysis. Records of daily mean temperature at Site 1 (70 m altitude) were derived from a database on the website of the Japan Meteorological Agency (2018), whereas those at Site 2-6 (210-800 m altitude) were estimated based on the temperature at Site 1 and a temperature lapse rate in relation to increasing altitude. The temperature lapse rate was calculated based on the actual air temperature recorded at Site 1 and Site 6 from 15 June to 7 August in 2016 using a TR-52 data logger (T\&D Corporation, Nagano, Japan) placed under the eaves.

\section{Diapause incidence of the low-altitude population}

To determine whether low-altitude populations are bivoltine, the incidence of embryonic diapause was examined in summer and autumn. On 16 July 2016, 11 females and 12 males were collected from Site 1. Adults were kept in a plastic container (150 mm diameter, $90 \mathrm{~mm}$ depth) under semi-natural conditions at Site 1: They were placed under the eaves of a hut, and thus they were protected from rain and direct sunlight under natural photoperiods and temperatures. In the same way, 11 females and 13 males 
were collected from Site 1 on 24-31 August 2016 and were reared under semi-natural conditions at Site 1. Eggs they laid were collected five times within one month after collection, and placed on moist cotton in a plastic cup under semi-natural conditions at Site 1. Dead eggs that became black and were covered with fungus were removed twice a week, and the diapause status of the other eggs was judged 35 days after collection. Eggs that had hatched were judged to be nondiapause whereas unhatched living eggs were in diapause (Masaki 1979).

\section{Body size of field collected adults}

The width of the head, including the compound eyes, was measured as an index of the body size, because this width is closely correlated with other dimensions of sclerotized parts of the body (Masaki 1978b). The head width was measured using a stereomicroscope (S8 APO; Leica Microsystems, Wetzlar, Germany) and ScopeImage 9.0 imaging software in adults that were collected from the six sites in September in 2015-2017 and preserved in 70\% ethanol. The head width of adults collected from Site 1 in July in 2017 was also measured and compared with that of adults collected from Site 1 in September, to determine whether the head width differed between diapause and nondiapause generations (Kivelä et al. 2013).

\section{Rearing experiments under semi-natural conditions}

Approximately 40 adults were collected from Site 1 and Site 6 in September 2015, and 
reared under semi-natural conditions at Site 1. Diapause eggs laid by them were allowed to overwinter under semi-natural conditions at Site 1 . When they hatched in the next spring, more than 160 nymphs were collected for each strain and reared under semi-natural conditions at Site 1 . The density of nymphs was kept at 60 per a plastic pot or fewer (70 mm diameter, $140 \mathrm{~mm}$ depth). After adult emergence in summer, 20 females and 20 males of each strain were kept in a plastic container. Eggs laid by them were collected six times within 40 days after emergence, and kept under semi-natural conditions at Site 1. Diapause status of these eggs was judged as shown above.

\section{Statistical analyses}

Analyses were carried out using $R$ 3.5.0 (https://www.r-project.org). A linear mixed effects model was applied to evaluate the effects of sex and altitude of the original locality on the adult head widths, using $R$ package nlme. Quadratic and cubic terms of altitude were also evaluated. We selected a parsimonious model based on Akaike's information criterion (AIC). The sampling year was treated as a random effect. Latitudes of localities were not included in the model because the differences were no more than $0.70^{\circ} \mathrm{N}$. Because it is expected that variance of the head width became larger at altitudes where univoltine and bivoltine life cycles coexisted than at altitudes where either of them existed, the head width of adults collected from the six sites in September 2017 was tested for homogeneity of variance, using $R$ package lawstat.

\section{RESULTS}




\section{Season length at different altitudes}

Actual mean air temperature from 15 June to 7 August in 2016 at Site 1 and Site 6 was $25.0^{\circ} \mathrm{C}$ and $21.0^{\circ} \mathrm{C}$, respectively, and therefore the temperature lapse rate was calculated to be $5.5^{\circ} \mathrm{C}$ per $1000 \mathrm{~m}$ elevation in altitude. The sum of effective temperature was estimated to decrease with increasing altitude from $2,418 \pm 79$ day-degrees at Site 1 to $1,541 \pm 80$ day-degrees at Site 6 (mean \pm S.D.).

\section{Diapause incidence of the low-altitude population}

The adults collected from Site 1 on 16 July and 24-31 August produced 509 and 1,304 eggs during one month, respectively. The incidence of embryonic diapause was $5.7 \%$ and $100 \%$ in the adults collected on 16 July and those on 31 August, respectively, under semi-natural conditions at Site 1.

\section{Body size of field collected adults}

There was an altitudinal variation in the adult head width in both sexes (Fig. 2). The head width increased with increasing altitude in each sampling year. Within each population, the head width was larger in females than in males. AICs of models including linear, quadratic and cubic terms of altitude were $-2,169,-2,195$ and $-2,153$, respectively. Results of the linear model including a quadratic term showed that both sex and the altitude of locality had significant effects on the head width (Table 1). The head width of females and males collected from Site 1 in July 2017 was $1.66 \pm 0.05$ and 
$1.55 \pm 0.05$, respectively (mean \pm S.D.), and did not differ significantly from that of adults collected from Site 1 in September (Welch's $t$ test, females, $P=0.20$; males, $P=$ 0.95). The body size showed a bimodal pattern at Site 3, whereas it showed unimodal or unclear patterns at the other sites (Fig. S1). Variance of the head width became largest at the middle altitude in both sexes, although there were significant altitudinal differences in variance of the head width of adults collected in September 2017 only in males (Levene's test, females, $P=0.37$; males, $P<0.001$ ).

\section{Rearing experiments under semi-natural conditions}

Diapause eggs laid by adults collected from Site 1 and Site 6 hatched in late May after overwintering, and adults emerged from August to September under photoperiods and temperatures corresponding to the natural ones at Site 1 (data not shown). The mean hatching date was 22 May $(n=2064)$ and 24 May $(n=161)$ for the strains from Site 1 and 6, respectively. Twenty females and 20 males of the strains from Site 1 and Site 6 that emerged in August produced a total of 2,004 and 2,234 eggs in 40 days, respectively (Fig. 3). The proportion of diapause eggs produced by the strain from Site 1 was approximately $50 \%$ in late August and then increased as the season progressed, whereas that produced by the strain from Site 6 was approximately $100 \%$ regardless of the month.

\section{DISCUSSION}

In P. mikado, the incidence of embryonic diapause showed that there was variation in 
voltinism along altitude. The incidence of diapause was very low in eggs laid by adults collected on 16 July 2016 from the low-altitude site, whereas all the eggs laid by adults collected on 24-31 August 2016 from the low-altitude site entered diapause. These results show that $P$. mikado populations are bivoltine at low altitude in the region around Kyoto. Adults of the low-altitude strain also produced a large proportion of nondiapause eggs during their early reproductive periods when they were reared from eggs under natural photoperiods and temperatures at the low-altitude site from spring to summer (Fig. 3). It is probable that these adults emerged later than adults of the natural population at the low altitude because they could not bask in the sun to regulate their body temperatures (Begon 1983; Chappell 1983). The increasing incidence of embryonic diapause from August to September is adaptive when the nymphal development of the overwintering generation is retarded, because the remaining length of the season is so short that the next generation cannot accomplish its growth and reproduction. In the high-altitude strain, however, the incidence of embryonic diapause was approximately $100 \%$ over their reproductive periods even though the parental generation was reared under natural photoperiods and temperatures at the low-altitude site. Together with the fact that no adult was found at Site 6 on 17 July 2016 (N. Matsuda personal observation), it is suggested that $P$. mikado populations are strictly univoltine at high altitude in the region around Kyoto, as at low altitude in the northern part of Japan (Masaki 1979). Comparison of the length of the growing season suggests that approximately 2,000 day-degrees over $11.7^{\circ} \mathrm{C}$ is supposed to be necessary for the bivoltine life cycle of $P$. mikado. In addition, these results show that the genetic propensity to enter diapause was higher in the high-altitude strain than the low-altitude strain. Therefore we conclude that the altitudinal variation in voltinism of $P$. mikado is 
based on the genetic difference in the incidence of diapause.

The adult head width of P. mikado was generally larger at higher altitudes, but slightly smaller at $800 \mathrm{~m}$ than at $670 \mathrm{~m}$ altitude (Fig. 2). The result of the linear mixed effects model including a quadratic term of altitude of locality and the comparison of AICs of models supported a U-shape relationship between the head width and altitude, which is thought to be a part of a saw-tooth cline (Table 1). Considering that populations at altitudes of 70 and $800 \mathrm{~m}$ were bivoltine and univoltine, respectively, this altitudinal cline in the head width can be explained by the change in the number of annual generations along altitude in the same way as the latitudinal saw-tooth clines in the head widths in P. mikado and D. nigrofasciatus (Masaki 1972, 1978b). The altitudinal variation in the head width should not result simply from the fact that the diapause generation became larger than the nondiapause generation. This is because the head width of adults collected from Site 1 in July did not differ significantly from that of adults collected from Site 1 in September, even though the former and the latter are supposed to develop from diapause and nondiapause eggs, respectively. The increase in the head width with increasing altitude from 70 to $670 \mathrm{~m}$ probably represents the transition from bivoltine to univoltine seasonal cycle and the increasing proportion of larger univoltine individuals with longer development time from low to high altitude. The large variance of the head width at the middle altitude can also be explained by coexistence of univoltine and bivoltine life cycles (Fig. S1). This reasoning does not contradict the fact that the proportion of adults was smaller at $385 \mathrm{~m}$ than at $70 \mathrm{~m}$ in altitude in mid-July 2017 (N. Matsuda personal observation). However, the head width was larger at $670 \mathrm{~m}$ than $800 \mathrm{~m}$ altitude, where the univoltine life cycle is expected to be maintained, as in other species of Orthoptera (Masaki, 1967; Berner \& Blanckenhorn 
2006; Bidau \& Martí 2007; Laiolo et al. 2013; Eweleit \& Reinhold 2014; Levy \& Nufio

2015). Therefore we conclude that the altitudinal variation in the head width was mainly resulted from the different lengths of the season available for growth, although lower temperature at higher altitudes might also be involved into the larger head width (Horne et al. 2018). This altitudinal cline in the head width of $P$. mikado matches the expected pattern of the adult body size in insects that have variable voltinism (Roff 1980; Chown \& Gaston 1999; Chown \& Klok 2003).

In conclusion, there was not only variation in voltinism and the body size but also the genetic difference in the incidence of diapause between the populations at altitudes of 70 and $800 \mathrm{~m}$ in P. mikado. The distance between the sites of these two populations was only approximately $5.7 \mathrm{~km}$. Keller et al. (2013) reviewed 68 previous studies that observed phenotypic differences between populations of 44 animal species, including 24 arthropods, at different altitudes. The distances between population sites ranged from 5 to $3,900 \mathrm{~km}$, with median distance of $135 \mathrm{~km}$. We therefore conclude that the genetic differentiation has been accomplished within a relatively short distance in P. mikado. The genetic differences in life-history traits between populations at different altitudes have also been examined in other species in Orthoptera, and significant genetic differences were shown in some of them. In the grasshopper Melanoplus sanguinipes in the U.S.A., the nymphal development time in the laboratory was shorter in insects collected from an altitude of 2,700 $\mathrm{m}$ than in those from an altitude of $90 \mathrm{~m}$ (Dingle et al. 1990). In the grasshopper Omocestus viridulus in Switzerland, both embryonic and nymphal development times in the laboratory decreased with increasing altitude from 410 to 2,440 m (Berner et al. 2004). In the ground cricket Allonemobius socius, populations collected from altitudes of 145 and 164 m showed higher plasticity in the 
incidence of embryonic diapause than populations collected from altitudes of 1,210 and $1,710 \mathrm{~m}$, and thus averted diapause during summer (Winterhalter \& Mousseau 2007). In Allonemobius fasciatus in the U.S.A., however, little or no genetic difference was detected in the incidence of embryonic diapause, postdiapause development or nymphal development time in the laboratory between populations collected from altitudes of 76 and $1,100 \mathrm{~m}$, although the hatching time differed by more than 1.5 months between the two populations (Tanaka \& Brookes 1983). It is probable that low dispersal ability reduces gene flow and therefore results in genetic differentiation in life-history traits between populations at different altitudes. Within the sampling localities in the present study, grass fields that P. mikado populations inhabited were distributed discontinuously. In addition, there were only a few macropterous adults of this species that were capable of long-distance dispersal in the present study (data not shown). These facts might have contributed to the altitudinal genetic differentiation in P. mikado.

\section{ACKNOWLEDGMENTS}

We thank Dmitry L. Musolin for critically reading the manuscript, and Elizabeth Nakajima for linguistic corrections in the manuscript submitted for publication.

\section{REFERENCES}

Alexander G, Hilliard JR (1969) Altitudinal and seasonal distribution of Orthoptera in the Rocky Mountains of northern Colorado. Ecological Monographs 39, 385-432. Atkinson D (1994) Temperature and Organism Size-A Biological Law for Ectotherms? Advances in Ecological Research 25, 1-58. 
Begon M (1983) Grasshopper populations and weather: the effects of insolation on Chorthippus brunneus. Ecological Entomology 8, 361-370.

Berner D, Blanckenhorn WU (2006) Grasshopper ontogeny in relation to time constraints: Adaptive divergence and stasis. Journal of Animal Ecology 75, 130-139. Berner D, Körner C, Blanckenhorn WU (2004) Grasshopper populations across $2000 \mathrm{~m}$ of altitude: Is there life history adaptation? Ecography 27, 733-740.

Bidau CJ, Martí DA (2007) Clinal variation of body size in Dichroplus pratensis (Orthoptera: Acrididae): Inversion of Bergmann's and Rensch's rules. Annals of the Entomological Society of America 100, 850-860.

Blanckenhorn WU, Demont M (2004) Bergmann and converse Bergmann latitudinal clines in arthorpods: Two ends of a continuum? Integrative and Comparative Biology 44, 413-424.

Chappell MA (1983) Metabolism and thermoregulation in desert and montane grasshoppers. Oecologia 56, 126-131.

Chown SL, Gaston KJ (1999) Exploring links between physiology and ecology at macro-scales: the role of respiratory metabolism in insects. Biological Reviews $\mathbf{7 4}, 87-$ 120.

Chown SL, Klok CJ (2003) Altitudinal body size clines: latitudinal effects associated with changing seasonality. Ecography 26, 445-455.

Dearn JM (1977) Variable life history characteristics along an altitudinal gradient in three species of Australian grasshopper. Oecologia 28, 67-85.

Dingle H, Mousseau TA, Scott SM (1990) Altitudinal variation in life cycle syndromes of California populations of the grasshopper, Melanoplus sanguinipes (F.). Oecologia 84, 199-206. 
Dmitriew CM (2011) The evolution of growth trajectories: What limits growth rate? Biological Reviews 86, 97-116.

Eweleit L, Reinhold K (2014) Body size and elevation: Do Bergmann's and Rensch's rule apply in the polytypic bushcricket Poecilimon veluchianus? Ecological Entomology 39, 133-136.

Higaki M, Ando Y (1999) Seasonal and altitudinal adaptations in three katydid species: Ecological significance of initial diapause. Entomological Science 2, 1-11. Hodkinson ID (2005) Terrestrial insects along elevation gradients: species and community responses to altitude. Biological Reviews 80, 489-513.

Horne CR, Hirst AG, Atkinson D (2018) Insect temperature-body size trends common to laboratory, latitudinal and seasonal gradients are not found across altitudes. Functional Ecology 32, 948-957.

Hut RA, Paolucci S, Dor R, Kyriacou CP, Daan S (2013) Latitudinal clines: an evolutionary view on biological rhythms. Proceedings of the Royal Society B: Biological Sciences 280, 20130433.

Keller I, Alexander JM, Holderegger R, Edwards PJ (2013) Widespread phenotypic and genetic divergence along altitudinal gradients in animals. Journal of Evolutionary Biology 26, 2527-2543.

Kivelä SM, Välimäki P, Gotthard K (2013) Seasonality maintains alternative life-history phenotypes. Evolution 67, 3145-3160.

Körner C (2007) The use of "altitude" in ecological research. Trends in Ecology and Evolution 22, 569-574.

Laiolo P, Illera JC, Obeso JR (2013) Local climate determines intra- and interspecific variation in sexual size dimorphism in mountain grasshopper communities. Journal of 
Evolutionary Biology 26, 2171-2183.

Levy RA, Nufio CR (2015) Dispersal potential impacts size clines of grasshoppers across an elevation gradient. Oikos 124, 610-619.

Masaki S (1960) Thermal relations of diapause in the eggs of certain crickets (Orthoptera: Gryllidae). Bulletin of the Faculty of Agriculture Hirosaki University 6, 520.

Masaki S (1967) Geographic variation and climatic adaptation in a field cricket (Orthoptera: Gryllidae). Evolution 21, 725-741.

Masaki S (1972) Climatic adaptation and photoperiodic response in the band-legged ground cricket. Evolution 26, 587-600.

Masaki S (1978a) Seasonal and latitudinal adaptations in the life cycles of crickets. In:

Dingle H (ed) Evolution of Insect Migration and Diapause, pp. 72-100. Springer, Berlin,

Masaki S (1978b) Climatic adaptation and species status in the lawn ground cricket. II. Body size. Oecologia 35, 343-356.

Matsuda N, Tanaka K, Watari Y, Shintani Y, Goto SG, Nisimura T, Izumi Y, Numata H (2018) Northward expansion of the bivoltine life cycle of the cricket over the last four decades. Global Change Biology 24, 5622-5628.

Mousseau TA, Roff DA (1989) Adaptation to seasonality in a cricket: patterns of phenotypic and genotypic variation in body size and diapause expression along a cline in season length. Evolution 43, 1483-1496.

Roff DA (1980) Optimizing development time in a seasonal environment: The "ups and downs" of clinal variation. Oecologia 45, 202-208.

Shelomi M (2012) Where are we now? Bergmann's rule sensu lato in insects. The 
American Naturalist 180, 511-519.

Tanaka S, Brookes VJ (1983) Altitudinal adaptation of the life cycle in Allonemobius fasciatus DeGeer (Orthoptera: Gryllidae). Canadian Journal of Zoology 61, 1986-1990. Tauber CA, Tauber MJ (1981) Insect seasonal cycles: genetics and evolution. Annual Review of Ecology and Systematics 12, 281-308.

Winterhalter WE, Mousseau TA (2007) Patterns of phenotypic and genetic variation for the plasticity of diapause incidence. Evolution 61, 1520-1531.

\section{SUPPORTING INFORMATION}

Additional Supporting Information may be found online in the Supporting Information Section at the end of the article.

Figure S1 Histograms of the head width of adult Polionemobius mikado collected from six sites at different altitudes in 2017. 
Table 1 Results of a linear mixed effects model to test the effects of variables including a quadratic term on the adult head width in Polionemobius mikado.

\begin{tabular}{lllll}
\hline Variables & Estimate & S.E. & $t$-value & $P$-value \\
\hline Intercept & 1.696 & $1.193 \times 10^{-2}$ & 142.123 & $<0.0001$ \\
Sex (male) & -0.1171 & $4.959 \times 10^{-3}$ & -23.622 & $<0.0001$ \\
Altitude & $4.363 \times 10^{-4}$ & $3.901 \times 10^{-5}$ & 11.186 & $<0.0001$ \\
Altitude $^{2}$ & $-3 \times 10^{-7}$ & $4.4 \times 10^{-8}$ & -7.878 & $<0.0001$ \\
\hline
\end{tabular}




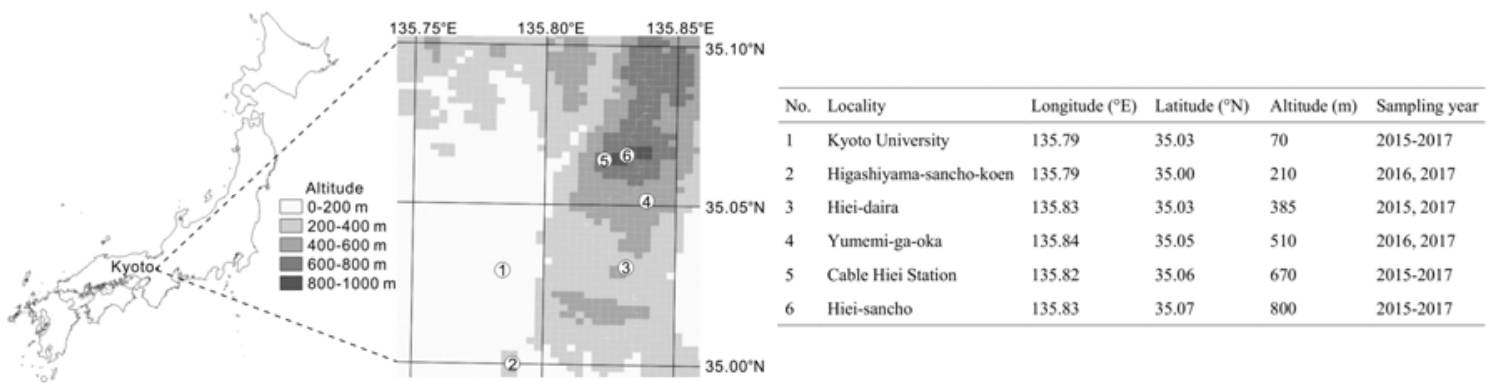

Figure 1 Sampling localities of Polionemobius mikado populations. Numbers in circles on the left panel correspond to location numbers in the table on the right panel. 


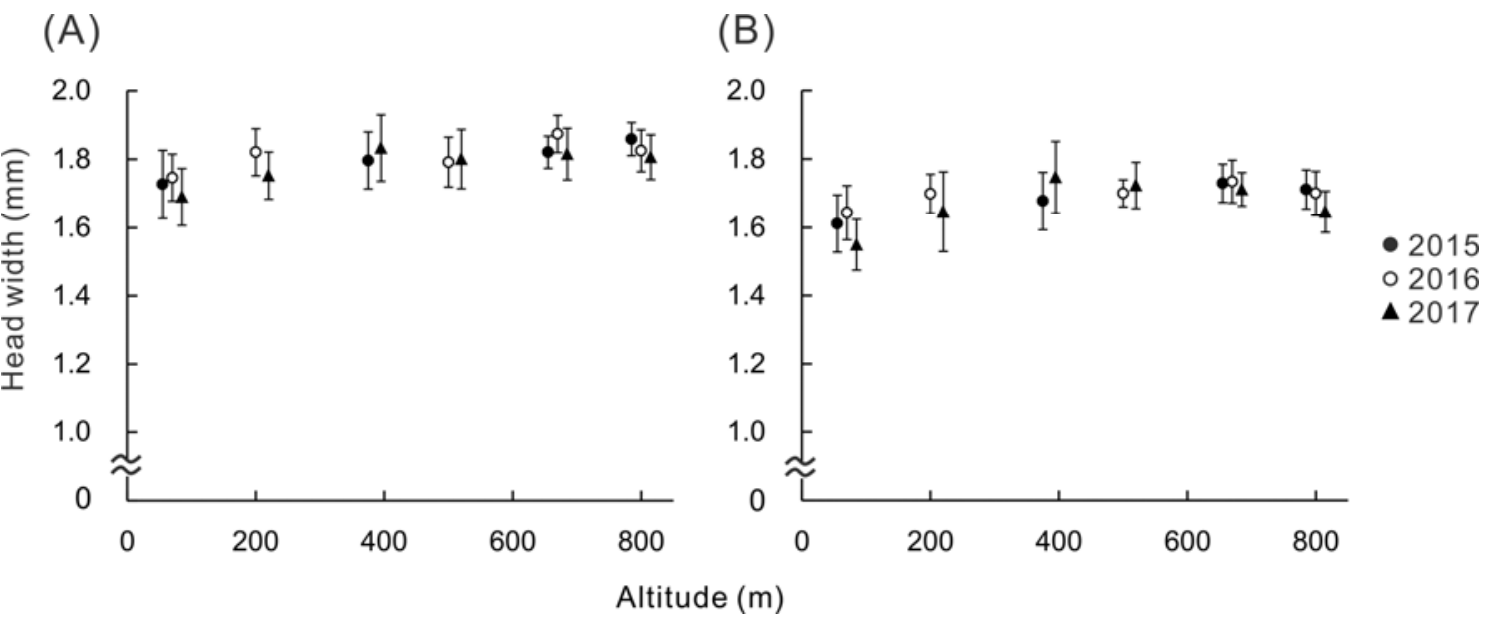

Figure 2 Head width of adult Polionemobius mikado in relation to altitude [mean \pm S.D., (A), females, $n=24-76$ for each symbol; (B), males, $n=10-47$ for each symbol]. Adults were collected in September, 2015-2017. 


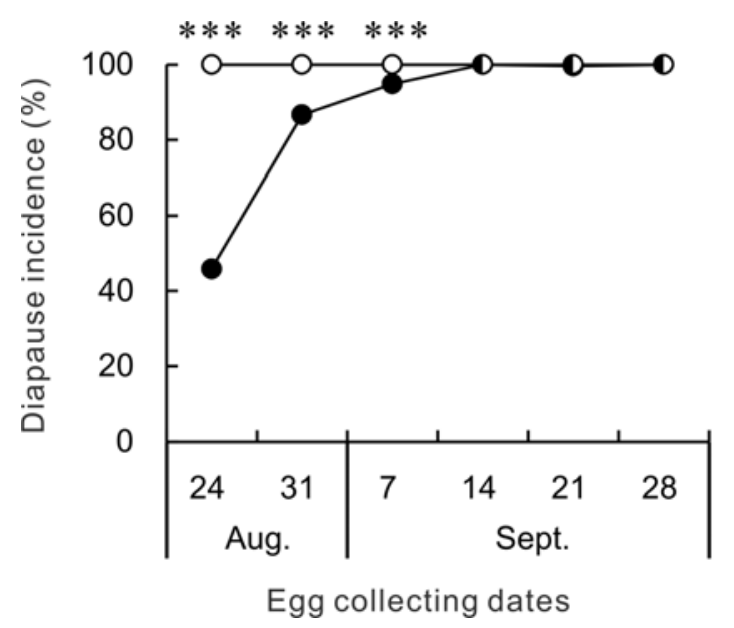

Figure 3 The incidence of embryonic diapause in progeny of Polionemobius mikado reared from eggs to adults under natural photoperiods and temperatures at altitude $70 \mathrm{~m}$. Closed and open circles show the progeny of adults collected from a site at altitude 70 $\mathrm{m}(n=19-704)$, and the progeny of adults collected from a site at altitude $800 \mathrm{~m}(n=$ 163-380), respectively. Asterisks indicate significant differences between the two strains (Chi-squared test, $* * * P<0.001)$. 